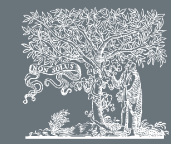

ELSEVIER

\title{
An acetylcholinesterase biosensor for determination of low concentrations of Paraoxon and Dichlorvos
}

\section{Di Tuoro ${ }^{1}$, M. Portaccio ${ }^{1,2}$, M. Lepore ${ }^{1,2}$, F. Arduini ${ }^{1,3}$, D. Moscone ${ }^{1,3}$, U. Bencivenga ${ }^{1,4}$ and D.G. Mita ${ }^{1,2,4}$,}

\footnotetext{
${ }^{1}$ National Institute of Biostructures and Biosystems (INBB), Rome, Italy

${ }^{2}$ Department of Experimental Medicine, Second University of Naples, Naples, Italy

${ }^{3}$ Department of Chemical Sciences and Technologies, University of Tor Vergata, Rome, Italy

${ }^{4}$ Institute of Genetics and Biophysics of CNR, Naples, Italy
}

The characterization of an economic and ease-to-use carbon paste acetylcholinesterase (AChE) based biosensor to determine the concentration of pesticides Paraoxon and Dichlorvos is discussed. AChE hydrolyses acetylthiocholine (ATCh) in thiocoline (TC) and acetic acid (AA). When AChE is immobilized into a paste carbon working electrode kept at $+410 \mathrm{mV}$ vs. $\mathrm{Ag} / \mathrm{AgCl}$ electrode, the enzyme reaction rate using acetylthiocholine chloride (ATCl) as substrate is monitored as a current intensity. Because Paraoxon and Dichlorvos inhibit the AChE reaction, the decrease of the current intensity, at fixed ATCl concentration, is a measure of their concentration. Linear calibration curves for Paraoxon and Dichlorvos determination have been obtained. The detection limits resulted to be $0.86 \mathrm{ppb}$ and $4.2 \mathrm{ppb}$ for Paraoxon and Dichlorvos, respectively, while the extension of the linear range was up 23 ppb for the former pesticide and up to $33 \mathrm{ppb}$ for the latter. Because the inhibited enzyme can be reactivated when immediately treated with an oxime, the biosensor reactivation has been studied when $1,1^{\prime}$-trimethylene bis 4-formylpyridinium bromide dioxime (TMB-4) and pyridine 2-aldoxime methiodide (2-PAM) were used. TMB-4 resulted more effective.

The comparison with the behavior of similar AChE based biosensors is also presented.

\section{Introduction}

Organophosphorus (OPs) pesticides are very toxic compounds, intensively used in agriculture because of their high insecticidal activity and their rapid mineralization in the environment [1] Their presence in the environment is very harmful for wildlife and human health as they irreversibly inhibit the catalytic activity of acetylcholinesterase (AChE), an enzyme which catalyzes the hydrolysis of the acetylcholine (ACh), one of the most important neurotransmitters playing a vital role in the central and peripheral nervous system [2,3]. Acetylcholine is believed to affect memory, sleep, concentration abilities. A short supply of acetylcholine is associated with Alzheimer's disease [3,4]. Due to their toxicologi-

Corresponding author. Mita, D.G. (mita@igb.cnr.it) cal activity some OPs have been used also as Chemical Warfare Agents (CWAs) [5,6].

In presence of these health risks, in recent years a growing attention has been paid in developing reliable, fast and inexpensive analytical systems to monitor this family of pesticides. Biosensors based on acetylcholinesterase, indeed, represent an emerging and promising technique for toxicity analysis, environmental monitoring, food quality control and military investigations [6-9]. The main application of AChE biosensors is the detection of OPs pesticides based on enzyme inhibition. Biosensors can substitute the current analytical methods, such as chromatographic and coupled chromatographic-spectrometric procedures, by simplifying or eliminating sample preparation, thus decreasing the analysis time and cost. The most critical point in the development of biosensors is the 
immobilization of the biological recognition element in an active form onto the electrode surface. Because the analytical performance of an electrode is strongly affected by this process, intensive efforts have to be made to develop effective immobilization methods, allowing improved operational and storage stability, response time, linear range and sensitivity, and preserving at the same time the enzyme affinity for the substrates or/and inhibitors. Physical entrapment of the enzyme has been used to immobilize enzymes because the absence of chemical bonds formation helps to preserve enzymatic activity during immobilization. However, the main drawbacks are the enzyme leaking and the possible diffusion barriers, imposed by the entrapping layer. Immobilization of AChE by simple incorporation into the graphite paste and by cross-linking with glutaraldehyde in a single or multi-layer deposition was accomplished $[10,11]$. Several biosensors functioning according to the principle of AChE inhibition have also been proposed [12]. Numerous prototypes based on potentiometric [13,14], amperometric [1517] and piezoelectric $[18,19]$ transducers have been developed. Because the enzymatic activity in AChE-based biosensors is destroyed upon calibration or in the presence of the analyte, the sensor must be discarded after determination [20,21], or, alternatively, the enzyme must be replaced [22-25] or reactivated [26,27].

In this paper we propose an economic and ease of use carbon paste AChE biosensor to detect OPs concentration in aqueous solutions. Once characterized, the biosensor has been employed in aqueous solution to detect the concentration of the pesticides paraoxon and dichlorvos, on the basis of their inhibitory effect on AChE activity. The conditions for the AChE reactivation have been reported, together with experiments of recovery studies of spilled real samples.

\section{Material and methods Materials}

Acetylcholinesterase (AChE, EC 3.1.1.7, Type VI-S, $10 \mathrm{kU} \mathrm{mg}^{-1}$, from electric eels), acetylthiocholine chloride (ATCl) and the oximes pyridine-2-aldoxime methoiodide (2-PAM) and 1,1'-trimethylene bis 4-formylpyridinium bromide (TMB-4) were purchased from Sigma (USA) and used as received. Paraoxon and Dichlorvos were also purchased from Sigma (USA), and their stock solutions were prepared in ethanol. Phosphate buffer solution (PBS) $0.1 \mathrm{M}$ at $\mathrm{pH} 7.5$, containing $0.1 \mathrm{M} \mathrm{KCl}$, was prepared by mixing stock solutions of $0.1 \mathrm{M} \mathrm{NaH}_{2} \mathrm{PO}_{4}$ and $0.1 \mathrm{M} \mathrm{Na}_{2} \mathrm{HPO}_{4}$. Carbon powder $(1.2 \mu \mathrm{M}$ in size) and mineral oil (employed as pasting material) were purchased from Sigma-Aldrich (Milan, Italy). All chemicals were of analytical reagent grade and all the aqueous solutions were prepared with redistilled deionized water.

\section{Biosensor design and fabrication}

Carbon paste was used to build up the working electrode. The carbon paste was prepared by hand mixing graphite powder, mineral oil and, when it was the case, acetylcholinesterase in an appropriate weight ratio. The resulting pastes were packed into the well of a Teflon tube ( $3 \mathrm{~mm}$ internal diameter and $1.2 \mathrm{~mm}$ in thickness) with an electrical contact provided by a copper wire. For economic reasons the Teflon tube was packed with a double layer of carbon paste. The inner layer contained only graphite powder mixed to mineral oil, and the outer layer composed of carbon paste, mineral oil and acetylcholinesterase. The inner layer, about

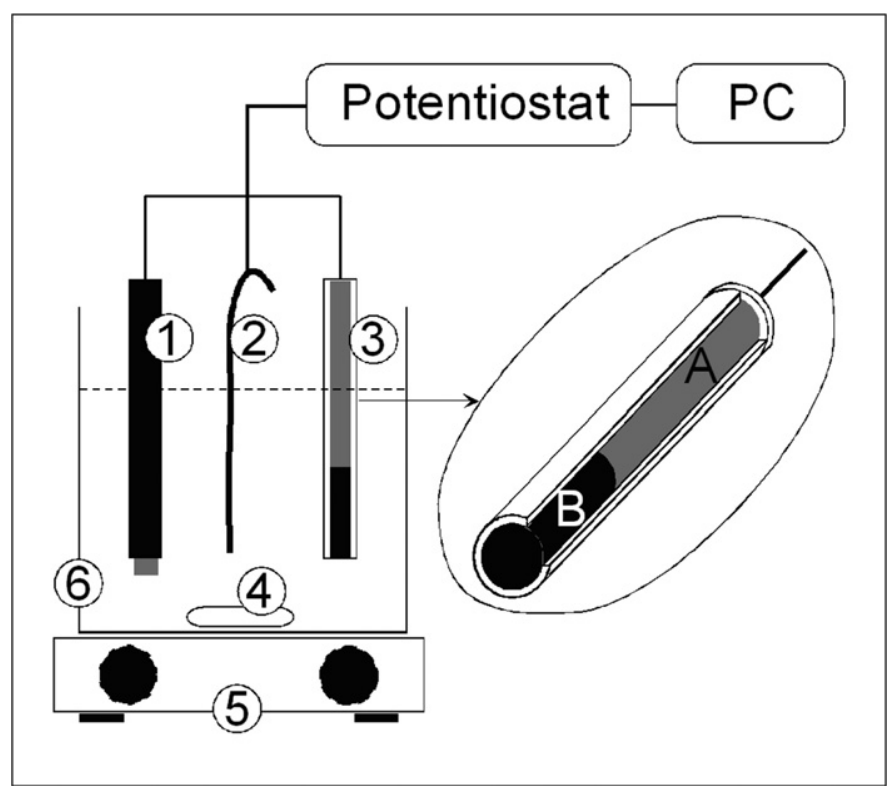

FIGURE 1

The electrochemical system: 1: Pb counter electrode; 2: $\mathrm{Ag} / \mathrm{AgCl}$ reference electrode; 3: working electrode, 4: magnetic bar; 5: magnetic stirrer; 6: electrolytic cell.

$2 / 3$ of the total volume, was prepared by mixing $60 \%$ of graphite powder and $40 \%$ of mineral oil, for a total weight of $4.8 \mathrm{mg}$. The outer layer, about $1 / 3$ of the total volume and with a total weight of $2.5 \mathrm{mg}$, was prepared by mixing graphite powder with mineral oil and acetylcholinesterase in the ratio (w/w) of 50:40:10, respectively. For each electrode we used about $0.25 \mathrm{mg}$ of acetylcholinesterase which corresponds to about $2500 \mathrm{U}$. The electrode surface was polished on weighing paper to give a smooth finish before use. Amperometric measurements were carried out using a PalmSens instrument (Palm Instruments, the Netherlands) coupled to a PC. All experiments were carried out in a three electrode electrochemical cell with a volume of $10 \mathrm{~mL}(0.1 \mathrm{M}$ sodium phosphate buffer, $\mathrm{pH} 7.5$, containing $0.1 \mathrm{M} \mathrm{KCl}$ ) with the enzyme modified CPE as working electrode, an $\mathrm{Ag} / \mathrm{AgCl}$ electrode as reference electrode and a platinum wire as auxiliary electrode (see Figure 1). The working electrode was operated at $+410 \mathrm{mV}$ vs. Ag/AgCl. A magnetic stirrer and a stirring bar provided the convective transport in the electrolytic cell. All measurements were performed at room temperature, that is $25.0 \pm 0.5^{\circ} \mathrm{C}$.

\section{Acethylthiocholine concentration measurements}

The acetylthiocoline concentration was determined by measuring the oxidation current of thiocholine according to the reaction occurring at the working electrode surface:

acetylthiocoline $+\mathrm{H}_{2} \mathrm{O} \stackrel{\mathrm{AChE}}{\longrightarrow}$ thiocholine + acetic acid

2 Thiocholine $($ red $) \rightarrow$ Thiocholine $($ ox $)$ (dimeric)

$+2 \mathrm{H}^{+}+2 \mathrm{e}^{-}$

\section{AChE inhibition experiments}

Experiments about inhibition measurements and pesticides concentration determination were carried out with $[\mathrm{ATCl}]=100 \mu \mathrm{M}$. To determine the pesticide concentration, the initial electrode 
response $\left(I_{0}\right)$ in presence of a known ATCl concentration and in the absence of the inhibitor is determined. Then the electrode is immersed in an aqueous solution containing the pesticide at a given concentration and incubated for $30 \mathrm{~min}$. After washing, the current intensity response $\left(I_{1}\right)$ is measured again under the initial standard conditions of ATCl. The inhibition percentage $I(\%)$ was determined according to the expression [9]: $I(\%)=\left[\left(I_{0}-I_{1}\right) / I_{0}\right] \times 100$. It is important to observe that the sample incubation and the electrochemical measurement are performed in two separate steps and among them a washing procedure is included.

The detection limit (LOD) corresponds to the amount of inhibitor which leads to the decrease of the signal equal to three times the standard deviation of the signal measurement [28-30].

\section{AChE reactivation experiments}

Immediately after the enzyme inhibition by organophosphorus pesticides, to restore its functionality an oxime should be administered [26,27]. Enzyme reactivation procedure was carried out according to Gulla et al. [26]. In brief, after biosensor was exposed to pesticide, it was washed with $\mathrm{PBS}(\mathrm{pH} 7.5,0.1 \mathrm{mM})$ and reactivated for $15 \mathrm{~min}$ with the oximes TMB-4 or 2-PAM, then transferred to electrochemical cell of $10 \mathrm{~mL} 0.1 \mathrm{PBS}$ at $\mathrm{pH} 7.5$ with $\mathrm{KCl}$ $0.1 \mathrm{M}$ containing $100 \mu \mathrm{M}$ ATCl to study the electrochemical response. The reactivation efficiency $(\mathrm{R} \%)$ was estimated as follows: $R_{0}(\%)=\left[\left(I_{\mathrm{r}}-I_{0}\right) /\left(I_{1}-I_{0}\right)\right] \times 100 \%$, where $I_{\mathrm{r}}$ was the steadystate current of ATCl at biosensor after reactivation, and $I_{1}$ and $I_{0}$ have the meanings as described above.

\section{Experimental data treatment}

Each experimental point in the figure is the average of five experiments carried out under the same conditions. The experimental error never exceeded 3\%. The operational stability of the electrode was more than 40 days. In fact, the electrodes were discarded when, after 40 days of two weekly use, the ATCl determination under standard conditions was changed of $20 \%$.

\section{Results and discussion}

First, we have studied the electrode response by varying the applied potential difference under constant ATCl concentration $(20 \mu \mathrm{M})$ and temperature $\left(25^{\circ} \mathrm{C}\right)$.

Results reported in Figure 2 show the biosensors response as function of the applied potential due to oxidation of thiocholine. It is observed an exponential increase of the current intensity according to a law of the type:

$I(p o t)=A e^{p o t / B}$

with $A=2.69 \pm 0.61 \mathrm{nA}$ and $B=240 \pm 20 \mathrm{mV}$.

Electrochemical oxidation of thiocholine may lead to dimerization products [31] causing fouling effects on the working electrode. This was observed at high potentials (from 500 to $700 \mathrm{mV}$ ) after few minutes of operation, whereas at an applied potential of $410 \mathrm{mV}$, the thiocholine response decreased significantly only after several hours of operation (data not shown). Due to the improved long-term applicability of the electrode, a potential of $410 \mathrm{mV}$ was used in the following investigation. Moreover, at $410 \mathrm{mV}$, the interference of other electro-oxidable chemicals present in real matrices to be analyzed is reduced. In Figure 3 the

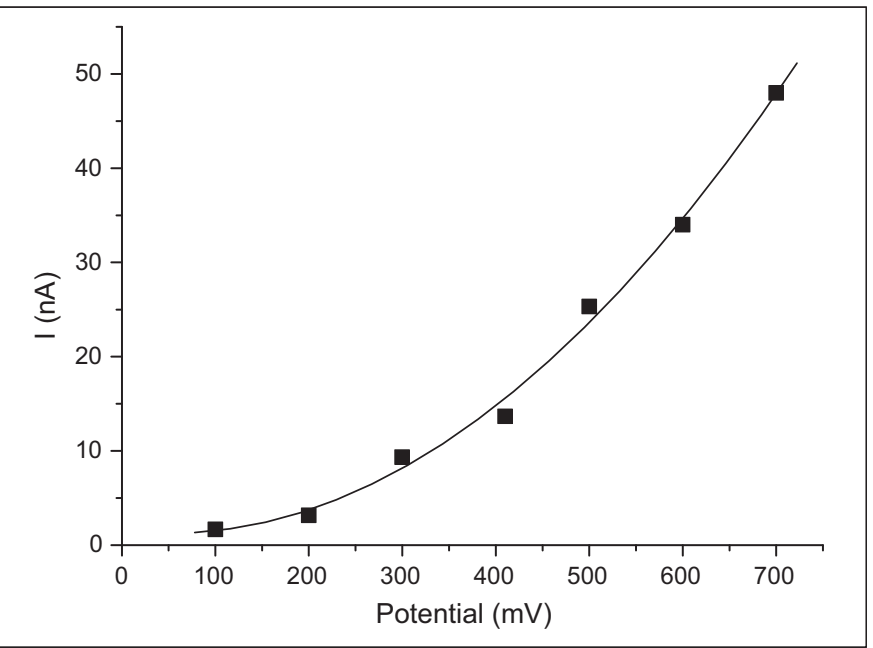

FIGURE 2

Oxidation currents as function of the applied potential. Experimental condition: $T=25^{\circ} \mathrm{C},[\mathrm{ATCl}]=20 \mu \mathrm{M}$ in phosphate buffer $0.1 \mathrm{M} \mathrm{pH} 7.5$ containing $0.1 \mathrm{M} \mathrm{KCl}$.

electrode response at different acetylthiocholine concentrations is reported. Data show a characteristic Michaelis-Menten kinetic mechanism. The apparent Michaelis-Menten constant $\left(K_{\mathrm{M} \text {,app }}\right)$ is the result of both the enzymatic affinity and the ratio of microscopic kinetic constants. The data of Figure 3 can be replotted in form of Lineweaver-Burk equation:

$\frac{1}{I}=\frac{K_{M, a p p}}{I_{\max }} \times \frac{1}{C}+\frac{1}{I_{\max }}$

where $I$ is the steady-state current after addition of substrate, $C$ is its bulk concentration, and $I_{\max }$ is the maximum current measured under saturated substrate conditions. The $K_{\mathrm{M} \text {,app }}$ value for AChEbiosensor was calculated to be $1.12 \pm 0.14 \mathrm{mM}$, while the value of $1.03 \pm 0.07 \mu \mathrm{A}$ for $I_{\max }$ was obtained. Insert in Figure 3 shows the linear calibration curve of our biosensor under the adopted experi-

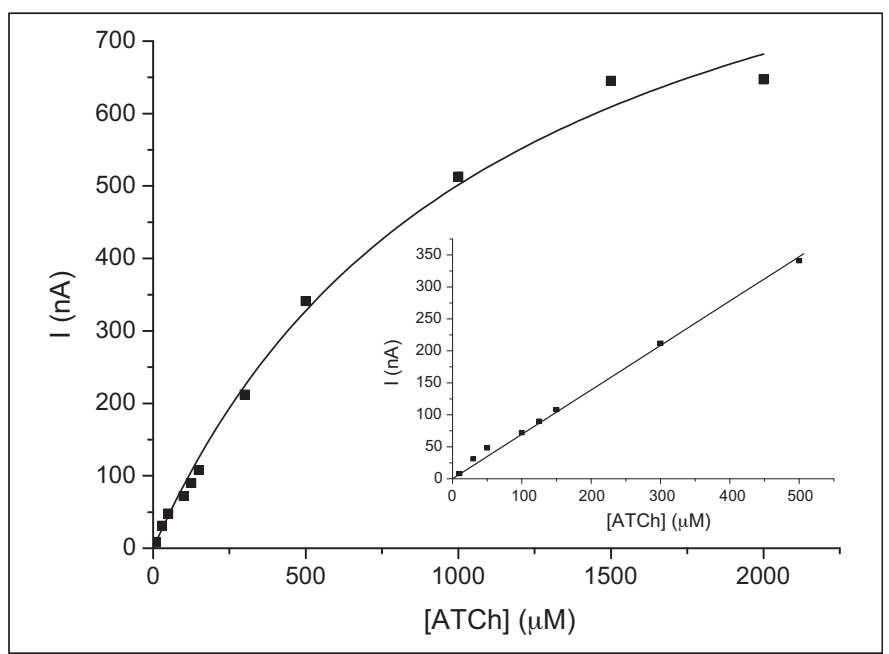

FIGURE 3

Current intensity response of $\mathrm{AChE}$ based biosensor: saturation currents as a function of ATCl concentration. Insert: the linear part of the curve is reported as calibration curve. 
mental conditions. From the data it is possible to obtain a value of $0.69 \pm 0.01 \mu \mathrm{A} / \mathrm{mM}$ for the biosensor sensitivity.

Having characterized our biosensor, we carried out experiments to determine the linear calibration curves for the pesticides of our interest.

The irreversible phosphorylation of the AChE active site when biosensors are incubated with pesticides leads to a decrease in the electrode response. The detection of the pesticides is quantified by measuring the AChE inhibition response as percent decrease of the current before and after inhibition, which is directly proportional to the concentration of pesticide in the tested solution.

Figure 4 shows the percentage inhibition of the current measured by the biosensor as a function of the pesticide concentration according to the reported methodology.

The acetylthiocoline concentration and the temperature were $100 \mu \mathrm{M}$ and $25 \pm 0.5^{\circ} \mathrm{C}$, respectively. In particular, results in

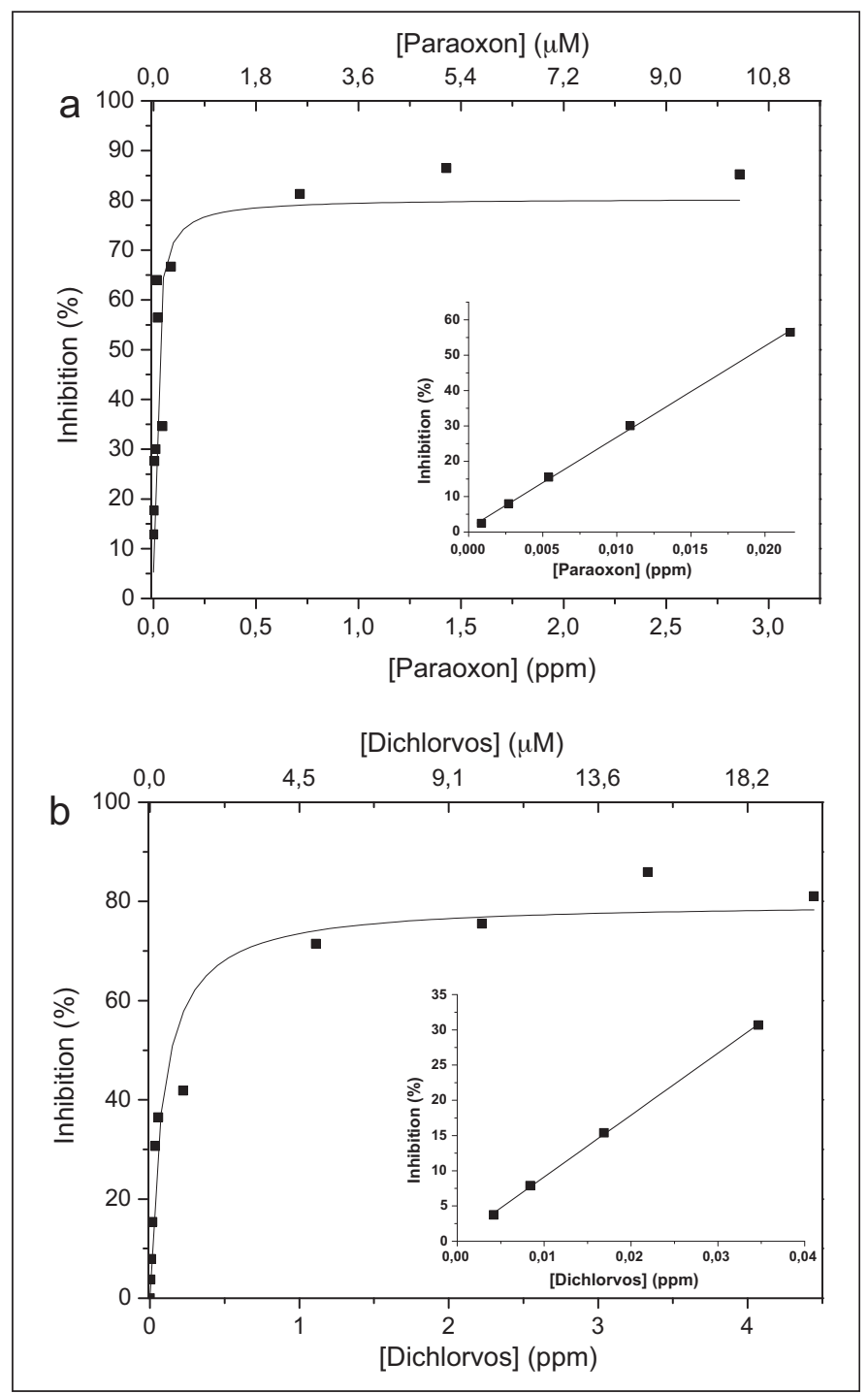

FIGURE 4

Percentage of inhibition as a function of pesticide concentration: (a) Paraoxon; (b) Dichlorvos. Inserts: the linear part of the curve is reported as calibration curve. Experimental condition: $T=25^{\circ} \mathrm{C}$, $[\mathrm{ATCl}]=100 \mu \mathrm{M}$ in phosphate buffer $0.1 \mathrm{M} \mathrm{pH} 7.5$ containing $0.1 \mathrm{M} \mathrm{KCl}$, applied potential: $+410 \mathrm{mV}$ vs. $\mathrm{Ag} / \mathrm{AgCl}$; pesticide incubation time $=30 \mathrm{~min}$.
Figure 4 refer to Paraoxon (Figure 4a) and to Dichlorvos (Figure 4b). For sake of clarity, double $x$-axis is introduced. In particular, lower axis reports concentrations in ppm, while in the upper axis the concentration is reported in $\mu \mathrm{M}$.

In both figures, the data of percentage of inhibition of the current intensity versus the pesticide concentration are well fitted by an hyperbolic function with a behavior similar to a MichaelisMenten dependence. The corresponding equations $\left(R^{2}=0.90\right.$ for Paraoxon and $R^{2}=0.96$ for Dichlorvos) allowed us to calculate the $K_{\mathrm{m} \text {,Inhib }}$ and the maximum inhibition percentage, IP $\mathrm{I}_{\max }(\%)$. For paraoxon these values resulted to be equal to $0.012 \pm 0.004 \mathrm{ppm}$ and $80.4 \pm 6.7 \%$, respectively. Similarly, the values of $K_{\mathrm{m}, \mathrm{In}}$ hib $=0.08 \pm 0.02 \mathrm{ppm}$ and $\mathrm{IP}_{\max }(\%)=79.8 \pm 3.8 \%$ were obtained for dichlorvos. The inserts in both figures show the linear calibration lines $\left(S=2575 \pm 47 \mathrm{ppm}^{-1}\right.$ for Paraoxon and $S=884 \pm 9 \mathrm{ppm}^{-1}$ for Dichlorvos) from which, knowing the percentage of inhibition, it is possible to determine the concentration of pesticide present in the aqueous solution.

Having ascertained the functionality of our AChE carbon paste modified biosensor in detecting the pesticides of interest, we have studied the enzyme reactivation after inhibition.

The oximes used are several and include, among other, TMB-4 and 2-PAM. These substances, when the phosphoester bond between the enzyme and the inhibitor is not too old, are able to remove the inhibitor from the enzyme active site by means of a transesterification reaction. On the contrary, if the enzyme is left inhibited for long time, in the absence of refill of any kind of oxime, it undergoes the so-called 'aging effect' [32,33], resulting in a permanent enzyme inhibition.

We have tested two oximes, TMB-4 and 2-PAM, finding that, at each concentration used, the former was more effective and that the optimal incubation time was $15 \mathrm{~min}$ (data not shown). In particular, with a Paraoxon concentration of $28.6 \mathrm{ppb}$ (corresponding to $0.1 \mu \mathrm{M})$, we have found that at the concentration of $3.5 \mathrm{mM}$ of each oxime, the 2-PAM exhibits a $76 \%$ of reactivation, while the AChE treated with TMB-4 shows a reactivation percentage higher than $95 \%$.

Just to give an example, in Figure 5 it is possible to observe the current intensity response of the biosensor in the absence of inhibition (trace 1), in the presence of inhibition by $15 \mathrm{~min}$ of exposition to $0.25 \mu \mathrm{M}$ paraoxon (trace 2 ) and after reactivation by $3.5 \mathrm{mM}$ TMB-4 (trace 3 ). In each case the final acetylthiocoline concentration in the reaction medium was $100 \mu \mathrm{M}$. It is interesting to observe that after reactivation, the biosensor response reaches quite the value obtained before the inhibition by paraoxon.

In Figure 6 the reactivation percentages are reported as a function of the pesticide concentration. The TMB- 4 concentration was $3.5 \mathrm{mM}$. As expected, the reactivation percentages decrease with the pesticide concentration, being total at lowest concentrations. Results in Figure 6 show that the complex pesticide/AChE is more resistant to the reactivation in the case of Dichlorvos. As for Paraoxon, the highest percentage of reactivation (90-100\%) is obtained with inhibitor concentrations ranging from $0.003 \mu \mathrm{M}$ and $0.5 \mu \mathrm{M}$; this percentage drops to a value of $60 \%$ for higher pesticide concentrations. Instead, in the case of Dichlorvos, it can be seen that the reactivation power is lower, with values of $30 \%$ for high pesticide concentrations. 


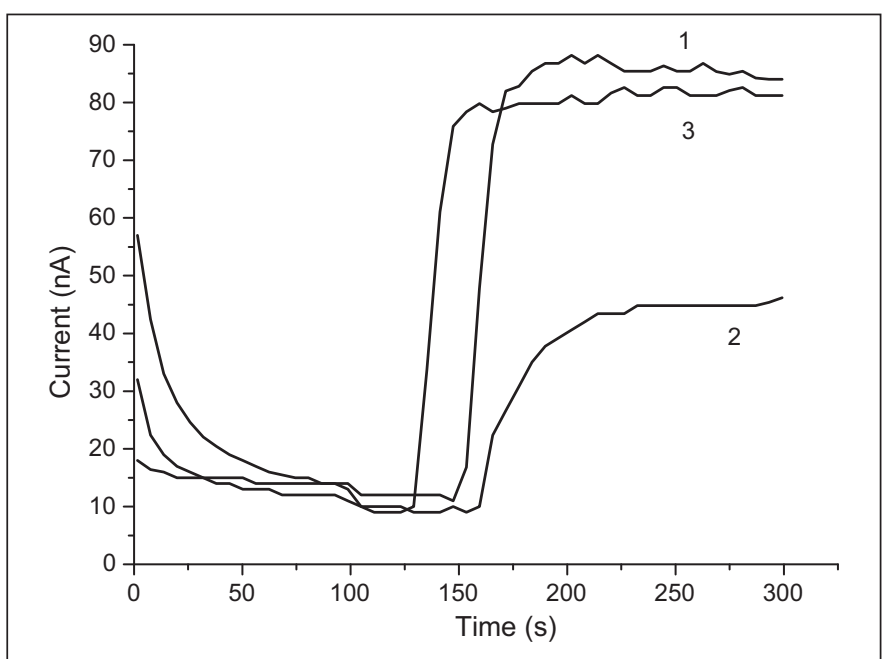

\section{FIGURE 5}

Current intensity measured in the absence of inhibitor (trace 1), in presence of inhibition (trace 2), after reactivation with $3.5 \mathrm{mM}$ TMB-4 (trace 3). Experimental condition: $T=25^{\circ} \mathrm{C}$, $[\mathrm{ATCl}]=100 \mu \mathrm{M}$ in phosphate buffer $0.1 \mathrm{M}$ $\mathrm{pH} 7.5$ containing $0.1 \mathrm{M} \mathrm{KCl}$, applied potential: $+410 \mathrm{mV}$ vs. $\mathrm{Ag} / \mathrm{AgCl}$; pesticide incubation time $=30 \mathrm{~min}$.

To challenge the biosensor with real samples, the biosensor was then tested using river water samples from two different sites in Agri River (Basilicata, Italy). The sites, identified as 1 and 2, were distant respectively about 1 or $2 \mathrm{~km}$ from the artificial lake 'Pietra del Pertusillo'. No inhibition was observed for our biosensor. To evaluate the accuracy of the biosensor, the samples were spiked with the two pesticides according to Arduini et al. [34]. Two different concentrations of Paraoxon or Dichlorvos were separately used. Table 1 shows the obtained results. A recovery of $87 \%$ and $140 \%$ was observed for Paraoxon, while a recovery varying between $83 \%$ and $120 \%$ was observed for Dichlorvos. The relative standard deviation (R.S.D.) of three successive measurements of the same sample was around of $5 \%$. These results demonstrate good recovery values and low matrix effect on the

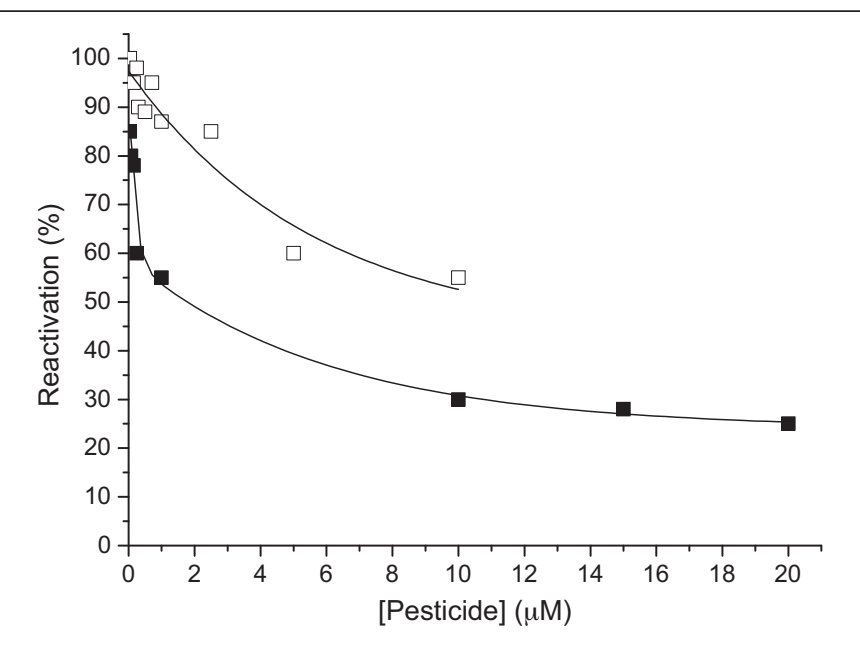

\section{FIGURE 6}

Reactivation percentages as a function of pesticide concentration. Symbols: $(\square)$ Paraoxon; ( $\square$ ) Dichlorvos.
TABLE 1

\begin{tabular}{llll}
\hline Recovery studies of spiked real water samples & \\
\hline Samples & $\begin{array}{l}\text { Paraoxon } \\
\text { concentration } \\
\text { added (ppb) }\end{array}$ & $\begin{array}{l}\text { Paroxon } \\
\text { concentration } \\
\text { found (ppb) }\end{array}$ & $\begin{array}{l}\text { Recovery } \\
\mathbf{( \% )}\end{array}$ \\
\hline Site $\mathbf{1}$ & 5 & 6 & 120 \\
& 15 & 13 & 87 \\
\hline Site $\mathbf{2}$ & 5 & 7 & 140 \\
& 15 & 14 & 93 \\
\hline Samples & Dichlorvos & Dichlorvos & $\begin{array}{l}\text { Recovery } \\
\text { concentration }\end{array}$ \\
& concentration \\
& added (ppb) & found (ppb) & \\
\hline Site $\mathbf{1}$ & 10 & 12 & 120 \\
& 30 & 32 & 107 \\
\hline Site 2 & 10 & 9 & 90 \\
& 30 & 25 & 83 \\
\hline
\end{tabular}

Experimental conditions: ATCl $(100 \mu \mathrm{M})$, applied potential: $+410 \mathrm{mV}$ vs. $\mathrm{Ag} / \mathrm{AgCl}$, phosphate buffer $0.1 \mathrm{M}+\mathrm{KCl} 0.1 \mathrm{M}, \mathrm{pH} 7.5$. Incubation time $=30 \mathrm{~min}$. All the values are mean of triplicate measurements.

biosensor signal. The low matrix effect is due to the procedure adopted for the pesticides measurement (see experimental part). In fact, using this method, it is possible to avoid electrochemical and enzymatic interferences [12]. Briefly, the electrochemical interferences, which can be present in the real sample tested, were eliminated because the residual enzymatic activity was measured in a new substrate phosphate buffer solution, in absence of real sample. In addition, the enzymatic interferences due to reversible inhibitors are avoided because after the incubation step, the biosensor is washed with distilled water and, in this way, only the inhibitor covalently linked to the enzyme (organophosphorus and carbammic compounds) is measured.

\section{Conclusions}

In this paper we have reported the results of the determination of the concentration of Paraoxon and Dichlorvos by means of an AChE carbon paste biosensors. The methodology was based on the inhibition of the activity of AChE entrapped in a mixture $(5: 4: 1$ by weight) of carbon paste, oil and AChE, respectively. The oxime TMB-4 resulted more effective than 2-PAM in reactivating the inhibited AChE.

Other properties of our biosensor are: (a) a detection limit of $0.86 \mathrm{ppb}$ for Paraoxon and of $4.2 \mathrm{ppb}$ for Dichlorvos; (b) an intraelectrode error never exceeding the $3 \%$, while the inter-electrode reproducibility was around 7\%; and (c) an operational stability of about 40 days.

To compare the characteristics of our biosensors with the ones of similar biosensors, we must remind, for example, that according to the literature, the detection limit of differently developed biosensors depends on the several parameters such as $\mathrm{pH}$, temperature, the immobilization matrix and the time of reaction between the enzyme and the inhibitor. Thus, direct comparison of the sensitivity between different biosensors is not easy and the cited parameters should be taken into consideration. Furthermore, the definitions of LOD and linear range are not unique. Therefore, to do this comparison, the LOD and linear range values of biosensors with design characteristics similar to our and taken from 
TABLE 2

LODs and linear ranges for amperometric AChE biosensors

\begin{tabular}{|c|c|c|c|c|}
\hline \multicolumn{2}{|c|}{ Paraoxon } & \multicolumn{2}{|c|}{ Dichlorvos } & \multirow[t]{2}{*}{ Ref. } \\
\hline $\begin{array}{l}\text { LOD } \\
\text { (ppb) }\end{array}$ & $\begin{array}{l}\text { Linear range } \\
\text { (ppb) }\end{array}$ & $\begin{array}{l}\text { LOD } \\
\text { (ppb) }\end{array}$ & $\begin{array}{l}\text { Linear range } \\
\text { (ppb) }\end{array}$ & \\
\hline 0.86 & $0.86-22.93$ & 4.2 & $4.2-33.16$ & Present paper \\
\hline $51.6^{a}$ & $51.6-154.8^{\mathrm{e}}$ & N.A. & N.A. & [35] \\
\hline $3^{b}$ & N.A. & N.A. & N.A. & [31] \\
\hline $2.86^{c}$ & N.A. & $2.21^{\mathrm{c}}$ & N.A. & [36] \\
\hline N.A. & N.A. & $0.69^{a}$ & N.A. & [37] \\
\hline N.A. & N.A. & $0.0025^{c}$ & $0.01-10^{\mathrm{e}}$ & [38] \\
\hline $0.29^{d}$ & N.A. & N.A. & N.A. & [39] \\
\hline N.A. & N.A. & $132^{a}$ & N.A. & {$[40]$} \\
\hline $0.3^{a}$ & N.A. & N.A. & N.A. & {$[41]$} \\
\hline $10^{d}$ & $14-173^{\mathrm{e}}$ & N.A. & N.A. & [28] \\
\hline N.A. & $300-1800^{f}$ & N.A. & N.A. & [26] \\
\hline $94^{d}$ & N.A. & N.A. & N.A. & [29] \\
\hline N.A. & N.A. & $0.02^{c}$ & N.A. & {$[42]$} \\
\hline $0.025^{a}$ & $0.025-0.175$ & N.A. & N.A. & [43] \\
\hline
\end{tabular}

N.A. stands for not available.

${ }^{a}$ LOD value corresponds to the concentration of the inhibitor for which there is $10 \%$ of inhibition.

${ }^{b}$ LOD value corresponds to the concentration of the inhibitor for which there is $5 \%$ of inhibition.

${ }^{c}$ No LOD definition.

${ }^{\mathrm{C}}$ LOD defined in as this paper.

e Linear range defined in function of log(pesticide concentration).

${ }^{\mathrm{f}}$ Linear range defined in function of pesticide concentration as in our paper. literature and reported in Table 2, have been integrated with the definitions used to obtain them. Examination of Table 2 shows that our results, even under the indicated limitations, can be competitive with the other reported in the table when a more attentive comparison is attempted. In fact, in some cases the better LOD is characterized by a very limited linear range (see for example ref. [41]) or LOD reaches a very low value only when different definitions of this parameter are given (see ref. [42], whose results were not reported in the table due to many different LOD definitions given along the paper).

Although many other technological approaches are nowadays available [44], in this work we have highlighted that optimising the operative conditions, it is possible to realize a simple biosensor based on enzyme immobilization in the carbon paste, which allows satisfactory results in terms of sensitivity and reproducibility. Moreover, the electrochemical surface can be easily renewed and the biosensor can be ready to use for successive analysis.

In addition we know that there are other more sensitive ACHE based biosensors, but these were done with engineered enzymes [45] and then they are more expensive.

In conclusions when economy and ease of use are mandatory, our biosensor can show characteristics better or comparable in respect to those obtained by other authors.

\section{Acknowledgements}

This work was has been supported by the Italian Consortium INBB with a fellowship to Daniela Di Tuoro, by the Italian Ministry of Health under the National Strategic Projects 'Salute della donna' (ISS/ISPESL) and 'Endocrine Disruptors' (ISPESL), and also by the Italian Ministry of Health/ISZM (Portici-Italy).

\section{References}

1 Jury, A.W. et al. (1987) Transport and transformations of organic chemicals in the soil-air-water ecosystem. Environ. Contamn. Toxicol. 99, 119-164

2 Bowen, D.M. et al. (1976) Neurotransmitter related enzymes and indices of hypoxia in senile dementia and other abiotrophies. Brain 99, 459-496

3 Deutsch, J.A. and Rogers, J.B. (1979) Cholinergic excitability and memory: animal studies and their clinical implications. In Brain acetylcholine and neuropsychiatric disease (Davis, K.L. and Berger, P.A., eds), pp. 175-204, Plenum Press

4 Fisher, A. et al. (1986) Alzheimer's and Parkinson's disease. In Strategies for research and development (Fisher, A., Hanin, I., Lachman, C., eds), pp. 141-146, Plenum Press

5 Sanchez-Santed, F. et al. (2004) Long-term neurotoxicity of Paraoxon and clorpyrifos: behavioural and pharmacological evidence. Neurotoxicol. Teratol. 26, 305-317

6 Noort, D. et al. (2002) Biomonitoring of exposure to chemical warfare agents: a review. Toxicol. Appl. Pharmacol. 184, 116-126

7 Leon-Gonzalez, M.E. and Townshend, A. (1990) Flow-injection determination of paraoxon by inhibition of immobilized acetylcholinesterase. Anal. Chim. Acta 236 267-272

8 Miroslaw, J. and Smogorzewski Shaul, G.M. (2008) Altered acetylcholine metabolism of brain in uremia: role of secondary hyperparathyroidism. I. Renal Nutr. 18, 122-126

9 Wilkins, E. et al. (2000) A quantitative determination of organophosphate pesticides in organic solvents. Electrochem. Commun. 2, 786-790

10 Albareda-Sirvent, M. et al. (2001) Thick-film biosensors for pesticides produced by screen-printing of graphite-epoxy composite and biocomposite pastes. Sens. Actuators B 79, 48-57

11 Albareda-Sirvent, M. et al. (2001) Pesticide determination in tap water and juice samples using disposable amperometric biosensors made using thick-film technology. Anal. Chim. Acta 442, 35-44 nerve agents and aflatoxin B1 detection (review). Microchim. Acta 170, 193-214

13 Ghindilis, A.L. et al. (1996) Potentiometric biosensors for cholinesterase inhibitor analysis based on mediatorless bioelectrocatalysis. Biosens. Bioelectron. 11, 873-880

14 Evtugyn, G.A. et al. (1996) Influence of surface-active compounds on the response and sensitivity of cholinesterase biosensors for inhibitor determination. Analyst $121,1911-1915$

15 Mionetto, N. et al. (1994) Acetylcholinesterase in organic solvents for the detection of pesticides: biosensor application. Biosens. Bioelectron. 9, 463-470

16 Palleschi, G. et al. (1992) Determination of organophosphorus insecticides with a choline electrochemical biosensor. Sens. Actuators B 7, 513-517

17 Skladal, P. and Mascini, M. (1992) Sensitive detection of pesticides using amperometric sensors based on cobalt phthalocyanine-modified composite electrodes and immobilized cholinesterases. Biosens. Bioelectron. 7, 335-343

18 Guilbault, G.G. and Ngeh-Ngwainbi, J. (1988) Analytical uses of immobilized biological compounds for detection, medical and industrial uses (. In Analytical uses of immobilized biological compounds for detection, medical and industrial uses (Guilbault, G.G. and Mascini, M., eds), p. 187, Reidel

19 Abad, J.M. et al. (1998) Determination of organophosphorus and carbamate pesticides using a piezoelectric biosensor. Anal. Chem. 70, 2848-2855

20 Hartley, I.C. and Hart, J.P. (1994) Amperometric measurement of organophosphate pesticides using a screen-printed disposable sensor and biosensor based on cobalt phthalocyanine. Anal. Proc. 31, 333-337

21 Kulys, J. and D'Costa, E.J. (1991) Printed amperometric sensor based on TCNQ and cholinesterase. Biosens. Bioelectron. 6, 109-115

22 Kindervater, R. et al. (1990) Exchangeable immobilized enzyme reactor for enzyme inhibition tests in flow-injection analysis using a magnetic device. Determination of pesticides in drinking water. Anal. Chim. Acta 234, 113-117 
23 Hart, A.L. et al. (1997) The response of screen-printed enzyme electrodes containing cholinesterases to organo-phosphates in solution and from commercial formulations. Biosens. Bioelectron. 12, 645-654

24 Palchetti, I. et al. (1997) Determination of anticholinesterase pesticides in real samples using a disposable biosensor. Anal. Chim. Acta 337, 315-321

25 Morelis, R.M. and Coulet, P.R. (1990) Sensitive biosensor for choline and acetylcholine involving fast immobilization of a bienzyme system on a disposable membrane. Anal. Chim. Acta 231, 27-32

26 Gulla, K.C. et al. (2002) Reactivation of immobilized acetyl cholinesterase in an amperometric biosensor for organophosphorus pesticide. Biochim. Biophys. Acta 1597, 133-139

27 Pohanka, M. et al. (2008) Improvement of acetylcholinesterase-based assay for organophosphates in way of identification by reactivators. Talanta $77,451-454$

28 Suprun, E. et al. (2005) Acetylcholinesterase sensor based on screen-printed carbon electrode modified with Prussian blue. Anal. Bioanal. Chem. 383, 597-604

29 Ivanov, Y. et al. (2010) Amperometric biosensor based on a site-specific immobilization of acetylcholinesterase via affinity bonds on a nanostructured polymer membrane with integrated multiwall carbon nanotubes. J. Mol. Catal. B: Enzym. 63, 141-148

30 Del Carlo, M. et al. (2005) Determining pirimiphos-methyl in durum wheat samples using an acethylcholinesterase inhibition essay. Anal. Bioanal. Chem. 381, 1367-1372

31 Gunther, A. and Bilitewski, U. (1995) Characterisation of inhibitors of acetylcholinesterase by an automated amperometric flow-injection system. Anal. Chim. Acta 300, 117-125

32 Kennedy, S.W. (1991) Cholinesterase-inhibiting insecticides: their impact on wildlife and the environment (Mineu, P., ed.), pp. 75-88, Elsevier

33 Okazaki, S. etal. (2000) Re-activation of an amperometric organophosphate pesticide biosensor by 2-pyridinealdoxime methochloride. Sens. Actuators B 66, 131-134

34 Arduini, F. et al. (2006) Detection of carbamic and organophosphorous pesticides in water samples using a cholinesterase biosensor based on Prussian Blue-modified screen-printed electrode. Anal. Chim. Acta 580, 155-162
35 Li, Y.G. et al. (1999) Immobilisation of enzyme on screen-printed electrode by exposure to glutaraldehyde vapour for the construction of amperometric acetylcholinesterase electrodes. Anal. Chim. Acta 382, 277-282

36 Hart, A.L. et al. (1997) The response of screen-printed enzyme electrodes containing cholinesterases to organo-phosphates in solution and from commercial formulations. Biosens. Bioelectron. 17, 645-654

37 Avramescu, A. et al. (2002) Biosensors designed for environmental and food quality control based on screen-printed graphite electrodes with different configurations. Anal. Bioanal. Chem. 374, 25-32

38 Sun, X. and Wang, X. (2010) Acetylcholinesterase biosensor based on Prussian blue-modified electrode for detecting organophosphorous pesticides. Biosens. Bioelectron. 25, 2611-2614

39 Khayyami, M. et al. (1998) Development of an amperometric biosensor based on acetylcholine esterase covalently bound to a new support material. Talanta 45, 557-563

40 Valdés-Ramírez, G. et al. (2008) Sensitive amperometric biosensor for dichlorovos quantification: application to detection of residues on apple skin. Talanta 74, 741-746

41 Jeanty, G. and Marty, J.L. (1997) Detection of paraoxon by continuous flow system based enzyme sensor. Biosens. Bioelectron. 13, 213-218

42 Valdés-Ramírez, G. et al. (2009) Automated resolution of dichlorvos and methylparaoxon pesticide mixtures employing a Flow Injection system with an inhibition electronic tongue. Biosens. Bioelectron. 24, 1103-1108

43 Jha, N. and Ramaprabhu, S. (2010) Development of Au nanoparticles dispersed carbon nanotube-based biosensor for the detection of paraoxon. Nanoscale 2, 806-810

44 Periasamy, A.P. et al. (2009) Nanomaterials - acetylcholinesterase enzyme matrices for organophosphorus pesticides electrochemical sensors: a review. Sensors 9, 4034-4055

45 Sotiropoulou, S. et al. (2005) Genetically engineered acethylcolinesterase-based biosensors for ottomolar detection of dichlorvos. Biosens. Bioelectron. 20, 2347-2352 